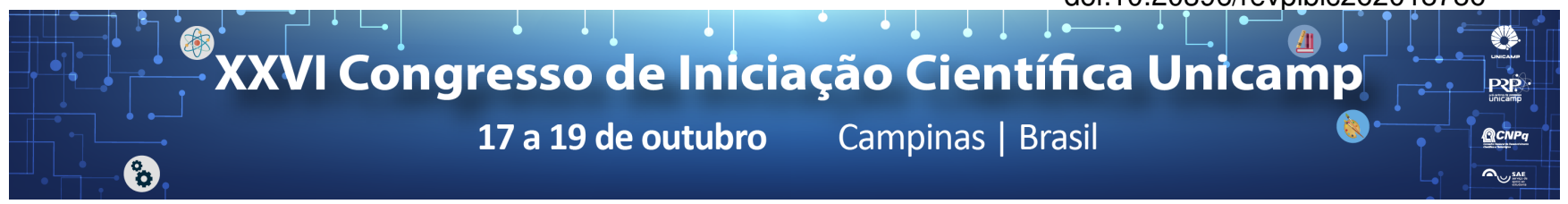

\title{
Modelagem Dinâmica da Marcha Humana de um Membro Inferior com 2 Graus de Liberdade
}

\author{
Larissa O. P. Frigerio*, Joao Mauricio Rosario
}

\section{Resumo}

Os exoesqueletos de auxílio à locomoção baseiam-se no comportamento biomecânico da marcha humana. Neste contexto, este trabalho fez um estudo dinâmico de três modelos que podem ser utilizados para um exoesqueleto de membro inferior com dois graus de liberdade. Assim, foram modeladas as estruturas serial, paralelogramo e híbrido (paralelogramo com compensação por mola), com base na equação de Lagrange.

\section{Palavras-chave: Modelagem dinâmica, Biomecânica, Marcha Humana}

\section{Introdução}

A Tecnologia Assistiva tem por objetivo fornecer e ampliar funcionalidades do corpo humano, de forma a proporcionar maior autonomia para aqueles que a usufruem. Neste sentido inserem-se os exoesqueletos, como os que auxiliam o processo de locomoção.

A partir do comportamento biomecânico durante a marcha humana, este trabalho fez um estudo dinâmico de três modelos que podem ser utilizados para um exoesqueleto de membro inferior com dois graus de liberdade. Assim, foram modeladas as estruturas serial, paralelogramo e híbrido (paralelogramo com compensação por mola), com base na equação de Lagrange:

$$
\frac{\mathrm{d}(\partial \mathrm{L} / \partial \mathrm{w})}{\mathrm{dt}}-\frac{3 \mathrm{~L}}{\partial w}=\tau
$$

sendo w: coordenada generalizada; $\tau$ : força generalizada; e L (Lagrangeano): a diferença entre energia cinética e potencial.

\section{Resultados e Discussão}

As modelagens foram feitas para o plano sagital, e considerou-se apenas dois graus de liberdade do membro inferior: rotação do quadril (ângulo entre a coxa e uma linha vertical) e a rotação do joelho (ângulo entre a perna e uma linha vertical).

Os três mecanismos estudados estão na Figura 1.

Conforme observa-se, a estrutura serial é composta por dois elos, que conectam o quadril, joelho e tornozelo. A do paralelogramo, por sua vez, possui a mesma disposição de elementos daquela do serial, acrescentados de duas barras que formam um quadrilátero com um dos vértices no joelho. Por fim, o mecanismo híbrido possui a mesma estrutura do paralelogramo acrescentado de duas molas. Rearranjando os termos da equação (I) de Lagrange, obtém-se que equações de na forma:

$$
\tau=J \ddot{w}+B \dot{w}+\tau_{r}
$$

sendo $\tau$ o torque necessário na junta para o movimento desejado, J o momento de inércia, B o atrito viscoso, $\tau_{r} 0$ torque resistente e w a posição angular para a junta. A partir da equação (II), foram modeladas as três estruturas. Em seguida, para cada uma delas, foi feita sua parametrização. Assim, obteve-se para cada grau de liberdade o momento de inércia, atrito viscoso e torque resistente em função de constantes, dependentes apenas de parâmetros geométricos e de massa.

Para cada um dos modelos, observa-se que sempre a equação obtida para o joelho é mais simples. Isso se deve porque a junta do quadril é bastante afetada pelos efeitos dinâmicos decorrentes do seu acoplamento com a junta do joelho.
Comparando-se os modelos, notou-se que o do paralelogramo tem constantes parametrizadas com valores maiores que a do serial. Isso porque a estrutura do paralelogramo possui duas barras a mais, que geram termos com massa e inércia maiores. Assim, seus valores gravitacionais aumentam em relação ao serial. Além disso, a posição do centro de massa do mecanismo também é diferente deste, dada a influência dessas barras (com suas próprias massas) adicionadas. Já o modelo híbrido possui valores gravitacionais menores do que o do paralelogramo. Isso acontece devido a presença das molas, que contribuem para a estabilidade deste modelo.
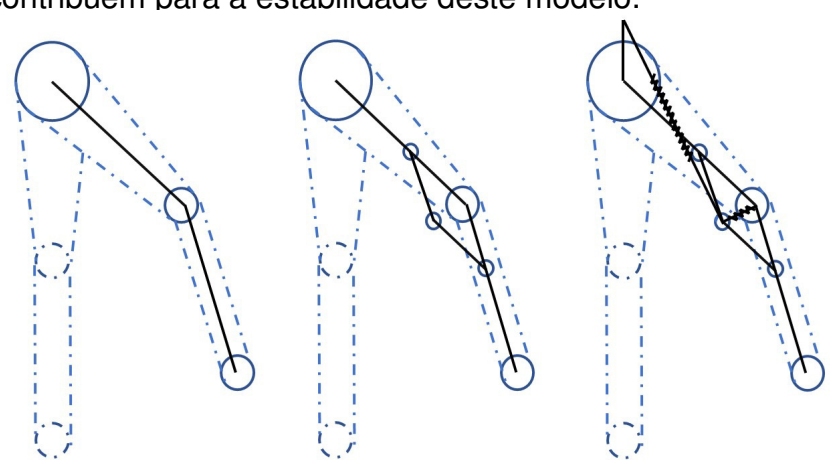

Figura 1. Da esquerda para direita: mecanismos serial, paralelogramo e híbrido

\section{Conclusões}

O mecanismo híbrido mostrou-se como aquele que seria mais estável, sendo o mais indicado dentre os três para um projeto de exoesqueleto.

Os próximos passos de estudo seriam acrescentar motores em cada uma das juntas e fazer o controle das mesmas, simulando e mostrando a validade da conclusão teórica obtida.

\section{Agradecimentos}

Ao meu orientador Prof. Dr. João Maurício Rosário, à minha família e amigos, e ao PIBIC/CNPq (proc. 100547/2018-4), que me apoiaram este trabalho.

WINTER, D. A. Biomechanics and Motor Control of Human Movement. Hoboken, NJ, USA: John Wiley \& Sons, Inc., 2009.

SPONG M. W. Hutchinson, S., and Vidyasagar, M., Robot Modeling and Control, John Wiley and Sons, 2006.

ROSÁRIO, J. M., Princípios de Mecatrônica. Prentice Hall, 2005. 